\title{
MEDIACIONES GENERIZADAS EN LA FORMACIÓN DOCENTE EN LETRAS
}

\author{
Valeria Sardi \\ Fernando Andino \\ Universidad Nacional de La Plata (Argentina)
}

\begin{abstract}
RESUMEN: En este artículo nos interesa presentar avances de una investigación en curso en la que indagamos en torno a las tensiones y sentidos en disputa en relación con el abordaje de género en la formación del profesorado en Letras universitario. Con el objetivo de problematizar e interpretar esas tensiones y sentidos analizamos una mediación docente en contexto en tanto puesta en juego que busca visibilizar y problematizar con estudiantes los estereotipos de género a partir de los emergentes que surgen en una clase de Literatura en una escuela secundaria como así también el interés de la docente en legitimar las voces de las estudiantes que, en el aula, estaban relegadas a una posición subalterna respecto de la hegemonía masculina (Molina Petit, 1994). Para ello consideramos incidentes críticos (Perrenoud, 1995) presentes en autorregistros realizados por una profesora en formación durante la residencia docente, relevados en la investigación en curso. Asimismo, indagaremos cómo en la intervención en el contexto se producen tensiones entre las corporalidades de los/as estudiantes -en tanto cuerpos festivos (Diez, 2012) - y el cuerpo de la profesora en tanto corporalidad replegada sobre sí misma y, asimismo, sus relaciones con la vergüenza e incomodidad fruto de la autopercepción de la docente como sujeto sexuado.
\end{abstract}

PALABRAS CLAVE: Género, formación docente, intervención didáctica generizada, incidentes críticos, corporalidad.

\section{TEACHER'S GENDER MEDIATION IN TEACHER TRAINING COURSE IN LANGUAGE ARTS}

\footnotetext{
ABSTRACT: In this article we are interested in presenting insights into an ongoing research project in which we study the tensions and senses in dispute regarding the gender approach in the university teacher training course in Language Arts. With the aim of putting into question and interpreting these tensions and senses, we shall analyze a teacher mediation in context as an
} 
operation that seeks to visibilize and question gender stereotypes with students from those emerging in a Literature class at a secondary school, as well as the teacher's interest in legitimizing the students' voices - which were relegated, in the classroom, to a subaltern position as regards male hegemony (Molina Petit, 1994). In relation to this, we intend to analyze critical incidents (Perrenoud, 1995) from self-registrations made by a teacher-in-training during her studentteaching period, recorded for this research. Additionally, we shall look into the tensions that arise from the intervention in context regarding the students' corporalities -inasmuch as they are festive bodies (Diez, 2012)- and the teacher's body as a corporality withdrawn in itself; and their connections to the shame and the discomfort that are caused by the teacher's self-perception as a sexed being.

KEYWORDS: Gender, teacher training course, generalized didactic intervention, critical incidents, corporality.

Recibido: 28/03/2017

Aceptado: 14/07/2017

Correspondencia: Valeria Sardi, Centro Interdisciplinario de Investigaciones en Género, Facultad de Humanidades y Ciencias de la Educación, Universidad Nacional de La Plata, C/51 entre 124 y 135, C.P. 1925, Ensenada, Provincia de Buenos Aires, Argentina. Email: sardivaleria@gmail.com.

\section{INTRODUCCIÓN}

Las aulas de escuelas secundarias se configuran como un territorio donde las regulaciones sexo-genéricas según los patrones patriarcales, sexistas y androcéntricos forman parte de la experiencia cotidiana escolar (Rockwell, 1995), observables tanto en el comportamiento de estudiantes como así también en ciertas representaciones de los docentes respecto del alumnado. De allí que el análisis de los modos de mediación didáctica en terreno en la formación docente inicial se presenta como una oportunidad para visibilizar y problematizar patrones institucionalizados en las prácticas escolares, tanto desde la perspectiva del estudiantado como desde el cuerpo docente, y contribuir a la formación de profesionales con conciencia de género.

El análisis que presentamos se enmarca en el proyecto de investigación en curso "La formación docente en Letras desde un abordaje de género: ¿una deuda pendiente?" radicado en el Centro Interdisciplinario de Investigaciones en Género del Instituto de Investigaciones en Humanidades y Ciencias Sociales de la Facultad de Humanidades y Ciencias de la Educación de la Universidad Nacional de La Plata (Argentina).

Un recorrido por el panorama de las investigaciones existentes nos permite observar distintas líneas de desarrollo: aquellas que se ocupan de indagar la desigualdad genérica en el acceso a la formación del profesorado (Fioretti, Tejero Coni y Díaz, 2002; Anguita Martínez, 2011); investigaciones que dan cuenta de cómo 
-a pesar de la existencia de un marco regulatorio- la perspectiva de género sigue estando ausente en el currículum y en las prácticas de enseñanza del profesorado (Donoso-Vázquez y Velasco-Martínez, 2013); también las que analizan el impacto del discurso de género del profesorado en la práctica docente (Jiménez Cortés, 2007); o bien, indagaciones vinculadas con las representaciones que el profesorado en España posee acerca de la relación género-poder (Bolaños Muñoz y Jiménez Cortés, 2007) o, también, aquellas que analizan prácticas y representaciones generizadas en la universidad (Aguilar, 2009; Ballarín Domingo, 2015; Blanco, 2014: Marrero y Mellada, 2009; Mora y Pujol, 2009). A diferencia de los desarrollos existentes, nuestro proyecto de investigación viene a dar cuenta de una vacancia en el campo en relación con cómo desde la formación docente inicial en Letras -en el ámbito universitario y no universitario- se configuran modos de hacer en la enseñanza de la disciplina que incluyen o soslayan la perspectiva igualitaria en relación con la producción, apropiación y circulación de saberes, en la conformación del canon teórico-literario y en relación con los modos de intervención docente en el futuro desarrollo profesional.

De allí que en este artículo analizaremos la intervención en terreno de una profesora en formación, durante su residencia docente en el Profesorado en Letras universitario, en clases de Lengua y Literatura en una escuela secundaria de una zona semirural de la periferia de la ciudad de La Plata (Pcia. de Buenos Aires-Argentina) y las estrategias y decisiones didácticas que va desplegando a partir de sucesivos incidentes críticos (Perrenoud, 1995) de género que se presentan a lo largo de las clases. Para ello, tomaremos como fuente para el análisis fragmentos de autorregistros (García Herrera, 2000) de la profesora en formación donde se recortan escenas de desajuste entre lo planificado y lo efectivamente concretado en la práctica, situaciones dilemáticas (Zabalza, 2004) donde se hizo necesaria su intervención en la urgencia de la práctica.

\section{LENGUAJE GENERIZADO Y EL DOBLE IMPOSIBLE}

Mariana, la profesora en formación que registró sus clases en el marco de la residencia, se propuso, desde un comienzo, problematizar con el alumnado la dimensión lingüístico-literaria, tanto desde la oralidad como desde la escritura y la lectura, para interpelar el cruce entre saberes disciplinares y saberes de género. En este sentido, decidió con su profesor-tutor -quien realiza el seguimiento de sus prácticas-al menos dos modos de intervenir para discutir "la lengua": la escritura de términos generizados en el pizarrón surgidos de la lectura de la novela Perros de nadie de Esteban Valentino que se estaba abordando en el aula y la producción de distintos soportes como por ejemplo las portadas de Facebook de Elisabeth, personaje travesti de la novela. En ambos casos, la discusión en torno a los modos de nombrar a personajes y sus prácticas, se planteaba como un espacio central en la episteme de la clase.

Veamos un recorte de su autorregistro que nos permitirá visualizar estos modos de intervención didáctica y sus resultados:

(...) Entonces indagué sobre los sentidos de "ser hombre" y fui anotando en el pizarón los conceptos que iban deslizando: de los varones venían palabras como "ser 
macho", "tenerlos bien puestos", y de las chicas, sobre todo de Alejandra, prejuicios como "lo femenino es de las mujeres". En un momento empezaron a mezclarse demasiadas opiniones que juntaban género, sexualidad, genitalidad, todo. Muchas de las opiniones homologaban la feminización con la homosexualidad. Antonio dijo "los hombres no nacen con el culo dado vuelta" y trajo a colación una anécdota un poco confusa que relataba la violación de un tío a un sobrino, que había ocurrido en Corrientes y que habría sido el origen de su homosexualidad. Lo contó con mucho desparpajo y entre risas. Incluso entendía que de alguna manera el chico "había dado permiso" para que eso sucediera. Casi como si no se tratara de una situación traumática y calificada legalmente como un delito. Él quiso usar ese relato como argumento de que "gay se hace" y que está muy ligado a las experiencias que uno vive. Confirmando un poco la teoría de Antonio, Mara dijo que había escuchado en la televisión que "a los 5 años uno decide si le gustan los varones o las mujeres". También Enrique contó un "caso" cercano, (...), que a los 15 años "se dio cuenta que era gay", pero que ya de chico "jugaba con muñecas". Por otra parte Octavio confrontaba estas opiniones intentando recuperar el sentido de las clases anteriores, y les decía a Ale y otros "qué tiene de malo ser gay".

La decisión didáctica de escribir "ser hombre" en el pizarrón e indagar los sentidos que provocaba esta frase dio lugar a la aparición -mediante comentarios- del lenguaje del alumnado en tanto lenguaje generizado. Desde los comentarios iniciales ("ser macho" o "tenerlos bien puestos" de los varones; "lo femenino es de las mujeres" de las alumnas), Mariana crea el escenario donde se presentará cada término y sus efectos $y$, por ende, la matriz binaria del curso. El lenguaje se convirtió en "cita" de la norma heterosexual (Butler, 2002, p. 37) que tanto alumnos, alumnas como la profesora ya venían tensionando en clases anteriores. Trabajar la lengua en este curso significó, entonces, discutir su poder performativo, entendido como "el poder reiterativo del discurso para producir los fenómenos que regula e impone" (Butler, 2002, p. 19).

Por otro lado, nos interesa pensar cómo esta profesora utiliza el entorno material del aula para provocar efectos didácticos sobre el lenguaje. La decisión de utilizar el pizarrón para escribir allí las frases del alumnado genera la relegitimación de sus hablas en esa clase. La escritura -en un lugar jerarquizado por la institución escuela para uso de agentes autorizados- de las voces y los términos que planteaba el alumnado relocaliza el lenguaje, lo vuelve extraño y lo dispone para ser reflexionado. Esta decisión didáctica resignificó cada término, creó y abrió la posibilidad de que aparecieran voces portando relatos autobiográficos de cada estudiante y argumentaciones sexo-genéricas en torno a lo que significa ser heterosexual y ser homosexual.

Junto a esta primera operación, Mariana da estatuto a la oralidad como herramienta didáctica para el abordaje del texto literario en la clase (Privat, 2001). De esta manera se coloca como moderadora de los debates que tuvieron lugar no solo formulando preguntas que discutan saberes disciplinares y de género sino, a la vez, indagando los silencios que se producían en el aula. Intenta establecer así una relación dialógica con el alumnado, cuyo espíritu reside en "la capacidad de mantener en suspenso muchos puntos de vista más el interés básico en la creación de un significado común" (Burbules, 1999, p. 45). En suma, la clase de Lengua y Literatura es planteada por Mariana a partir de opiniones, anécdotas y 
teorías del estudiantado que van interactuando con sus intervenciones y construyendo, a la vez, un saber local (Palermo, 2014) sobre el género y las sexualidades.

Otro aspecto relevante dentro de las decisiones de la profesora fue la elección del libro y la discusión en torno a uno de los personajes: Hugo es carpintero de día y travesti de noche. El incidente citado se sitúa justo en el momento donde se está por develar esta doble construcción del personaje. Mariana tiene en el horizonte ese detalle y prepara el camino para dar la discusión. El debate en torno al lenguaje generizado que coloca en escena apunta a discutir el marco binario que da sentido a las masculinidades hegemónicas. Y lo logra al tensionar la frontera dentro de la cual algunos de sus alumnos ocupan territorios de dominación. Como explicamos al comenzar el análisis, los primeros comentarios del alumnado colocaron el intercambio sobre el lenguaje en un marco heteronormativo. Sin embargo, las explicaciones de algunos alumnos varones dieron cuenta de lo otro de lo cual debían diferenciarse. La frontera así "existe (como) dimensión simbólica que opera para darle sentido a la experiencia de lo propio y lo ajeno" (Maffia, 2009, p. 218). En este sentido, los términos y las metáforas sexistas utilizadas por el alumnado irán designando un espacio-otro habitado por la homosexualidad y por la transexualidad más adelante. Este es el marco de poder lingüístico generizado que Mariana se propone desactivar para construir relaciones de género más igualitarias.

La intervención de Antonio da cuenta de esa tensión ("los hombres no nacen con el culo dado vuelta") para luego demostrar su silogismo generizado: si nacés hombre y te violan te "dan vuelta el culo" y te convertís en gay. La pelea de sentidos entre una mirada esencialista y una mirada performativa hace que algunos alumnos varones tengan que justificarse. Mariana logra, entonces, hacer visible el género detrás de la lengua. La preocupación por justificarse de sus alumnos da cuenta de cómo se construye la masculinidad en el aula. La lengua dice más: los varones deben demostrar que son viriles y pertenecen al sector masculino hegemónico. La asociación "ser macho=no ser violado" da cuenta de cómo "los chicos siguen siendo por tradición socializados escolarmente para desenvolverse de manera activa en lo público y diferenciarse todo el tiempo de todo aquello que los pueda inscribir como femeninos o como no heterosexuales" (Diez Gutiérrez, 2015, p. 81).

Al otorgarle entidad a la metáfora de Antonio, Mariana está dando cuenta de su postura frente a la enseñanza de la lengua, esto es, interpelar la lucha de sentidos que pugnan por imponerse y discutir que la dimensión de género es capital en esas representaciones. El "culo dado vuelta" es una imagen que refuerza la asociación de la homosexualidad a "lo abyecto", entendido como oposición al yo, como excluido, como inasimilable (Kristeva, 1988). Es una sinécdoque que esencializa, estigmatiza y arroja más allá de la frontera a los varones por sus orientaciones sexuales no hegemónicas. La operación de este discurso dominante se focaliza en el ano castrado del varón, condición sine qua non para ser y pertenecer a una masculinidad hegemónica. Como señala Beatriz Preciado (2013):

En el hombre heterosexual, el ano, entendido únicamente como orificio excretor, no es un órgano. Es la cicatriz que deja en el cuerpo la castración. El ano cerrado es el precio que el cuerpo paga al régimen heterosexual por el privilegio de su masculinidad. (pp. 12-13) 
La justificación de Antonio sobre la homosexualidad de su primo opera invirtiendo la enunciación. Es él mismo el que se está diferenciando, como joven heterosexual dominante, ante la mirada de sus pares de curso y de la profesora. Él expone así su pertenencia al grupo de varones con el ano castrado.

Bajo la misma hipótesis de que "homosexual se hace y no se nace", opera la anécdota de Enrique, ya no asociando homosexualidad a violación sino a una práctica -supuestamente-femenina: el juego con muñecas. De la misma manera que el concepto de "violación" en Antonio, el "jugar con muñecas" justifica la orientación sexual desviada de su primo, da origen a lo otro de lo que se quiere diferenciar el enunciador. Cuando Mara Lesbegueris analiza los juegos infantiles como prácticas donde se refuerza el género concluye: "Al hablar de juegos femeninos y/o masculinos, resaltamos la finalidad estratégica binaria sustentada bajo el orden heterosexual, donde las mismas estructuras del jugar crean y limitan la categoría 'niñas'" (2014, p. 163). Enrique justifica la orientación sexual de su primo dándole origen en el juego con muñecas. Otra vez, se apela a un orden binario para diferenciarse del otro. La enunciación vuelve a interpelar la frase del pizarrón "ser hombre". Ahora no se trata de un abuso sino de una práctica peligrosa para el varón. Práctica que lo desviaría de la norma y lo acercaría a lo opuesto constituido por la femineidad y la homosexualidad en tanto géneros subalternos.

Dentro de este marco binario también se ubica la intervención de Alejandra que Mariana toma como un prejuicio: "Lo femenino es de las mujeres". La demarcación territorial continúa reforzándose: de un lado de la línea se ubicarían los masculinos heterosexuales y del otro las mujeres y los homosexuales. Solo al final del recorte etnográfico vemos a Octavio tensionando esta división fuertemente estereotipada al cuestionar las acusaciones de sus compañeros sobre la condición de homosexualidad ("qué tiene de malo ser gay").

En este alumnado, el lenguaje generizado entra en tensión. Las metáforas en torno al ano y la alusión al juego con muñecas se resignifican en el pizarrón al ser escritas por la profesora del curso. Es allí, en ese lugar legitimado por la escuela y en el debate posterior, donde emerge el saber y el poder dominante de la lengua. Esas frases portan saberes en torno al género que toman la forma -por ejemplo en Antonio y en Enrique- de una pesquisa policial: ellos saben por qué alguien se convierte en gay, ellos saben las causas y descubren a los culpables. Son los detectives masculinos que -detectando la desviación- buscan exculparse señalando a los sospechosos. Así se convierten en hombres, diferenciándose de los que tienen "el culo dado vuelta" o practican juegos femeninos. Alejandra, por su lado, encierra lo femenino en las mujeres mientras que Octavio, al final del autorregistro, interviene intentado desmarcarse del sistema binario que reproduce el lenguaje.

Toda esta reflexión en torno al lenguaje y su relación con el género tuvo lugar en el aula a raíz de la intervención de Mariana. Su posición contrahegemónica, política y didáctica a la vez, respecto al lenguaje sexista dado en un marco androcéntrico y patriarcal habilitó -mediante la visualización de las expresiones del alumnado en el pizarrón y del diálogo- reflexiones que apuntaron a desnaturalizar las relaciones desiguales de poder entre los géneros. 
La discusión sobre el lenguaje generizado precedió a la lectura de una escena decisiva en la construcción del personaje Hugo/Elizabeth. Transcribimos el fragmento del autorregistro donde se devela esta doble personalidad en la novela y los efectos sobre los lectores y las lectoras en el aula:

(...) Cuando les pedí que reconstruyeran la escena que habíamos leído, la mayoría de ellos -con mucha naturalidad- decía que a Hugo le había pasado lo mismo que a Elizabeth. Incluso Marcos dijo que no lo habían reconocido "porque estaba oscuro". Dejé que por un momento esa coincidencia los hiciera reaccionar pero no sucedió. Entonces decidí retomar la lectura de los pasajes, poniendo especial acento en esa coincidencia imposible. Creo que fue Ari el primero en darse cuenta y decir "trabaja de trava". Esa ayuda de Leonel provocó el comentario de María "¡¿o sea que es un chabón?!", y la profunda indignación de Mati, que me reprochaba "iiocho clases hablando de Elizabeth y ahora me vengo a enterar que es un chabón!!". Marcos dijo "pobre Octavio, parece que se había enamorado". Leonel y Rodrigo comentaban que durante la primera parte se había dicho un montón de veces "que estaba buena" y ahora "es un tipo". Para Ale, la principal preocupación era "cómo hacía para trabajar si tenía partes de hombre". Le dije que hablar de partes sonaba a un auto con puertas de un modelo y ruedas de otro. Estela deslizó su hipótesis acerca de porqué Hugo elegiría ese trabajo y dijo "seguro no le alcanza el dinero", Marcos la secundó y agregó que entonces "tiene doble identidad". Octavio seguía muy indignado con el descubrimiento y decía que ahora no "tenía sentido". Yo, un poco entre risas por lo espontáneo de su reacción, le decía que este giro no impedía que siguiera gustándole el personaje de Elizabeth, que lo único que nos revelaba era que es un travesti. Ya estábamos muy próximos a la hora de irnos y Octavio recordó un cuento/novela que habían leído otro año en el cual una chica usaba a otra como su sustituta para relacionarse con un hombre que había conocido virtualmente, porque no se animaba a mostrar su verdadero cuerpo. Fue interesante ver cómo en sus horizontes de expectativas/experiencias, en primer lugar, la posibilidad de que aparezca una identidad disidente no estaba habilitada y, en segundo lugar, ver cómo se sentían de alguna manera estafados o engañados como lectores, ante eso que siempre estuvo en la historia sin necesidad de ser revelado en letras mayúsculas.

Es importante entender que Mariana, como profesora en formación, está construyendo con esta metarreflexión sobre sus prácticas los lineamientos de una didáctica de la lengua y la literatura. El interrogante de cómo gestionar la lectura de textos literarios en el aula fue central en su práctica en terreno. Desde esta arista vemos cómo decidió la lectura de Perros de nadie: "Dejé que por un momento esa coincidencia los hiciera reaccionar pero no sucedió. Entonces decidí retomar la lectura de los pasajes, poniendo especial acento en esa coincidencia imposible". Mariana lee y espera el reconocimiento del personaje. No sucede y vuelve a leer pasajes. Fragmentar la novela es otra decisión didáctica a tener en cuenta ya que la profesora focaliza su participación en un personaje que considera "imposible" para la configuración heterosexual de su curso. Por lo tanto, sus pausas, sus esperas, su modo de leer, la fragmentación del texto literario y el personaje elegido hablan de decisiones didácticas generizadas que, además de enseñar saberes lingüístico-literarios, interpelan fuertemente la dimensión sexo-genérica.

En cuanto al incidente crítico, vemos cómo la expectativa de algunos lectores varones aparece desestabilizada ante la incongruencia del personaje doble: para muchos de ellos Elisabeth no puede ser Hugo. La estafa, como indica Mariana, reside 
en la imposibilidad de pensarla a Elisabeth como travesti, en primer lugar; y que su doble fuera justamente Hugo, en segundo. Vemos cómo las discusiones que analizamos anteriormente ya marcaban una agrimensura de lo posible: si se era gay había un motivo, un origen que daba comienzo a ese mal -llámese violación o el juego con muñecas-. En este caso, la figura del travesti imaginado por el alumnado masculino parece desplazarse del que está planteado en la novela. Octavio, por ejemplo, discute ese personaje desde su construcción literaria, su "ahora no tiene sentido" lo vuelve inverosímil. De esta manera se muestra como lector estafado. Pero la escena no termina ahí ya que su asombro lo ubica en el centro de las burlas de sus compañeros al mostrarlo como "enamorado" de una mujer sobre la cual "se había dicho un montón de veces 'que estaba buena' y ahora 'es un tipo'". De esta manera se desestabiliza la masculinidad de Octavio y su pertenencia al grupo hegemónico. Su gusto por Elisabeth, al comienzo de la novela, lo desplaza por fuera de la línea divisoria que aparentemente domina el género en el aula una vez que se sabe su verdadero género: si le gustara una travesti ya no sería hombre.

Por otro lado, la perturbación que provoca esta "doble identidad" del personaje en algunos alumnos puede pensarse originada por la aparición de lo otro ominoso en la trama de la novela. Asociar la figura del travesti a lo monstruoso es una operación posible dado que tanto

(...) los trans como los hermafroditas tienen una cosa en común: (...) reúnen el símbolo máximo de la expresión de la masculinidad: el pene, con el de la femineidad. Su versatilidad al asumir tanto el rol activo como el pasivo los convierten en seres polifacéticos, mujer y hombre a la vez, sin ser ni una cosa ni otra, que pertenecen a un tercer género, intermedio, convertido en seres híbridos. (Rodríguez González, 2010, p. 153)

No se trata solamente de adjudicarle a Octavio una inclinación sexual determinada para burlarse. Se trata más bien de hacerlo víctima del engaño de la hibridez travesti y de asociarlo con ese terreno desconocido. Si en el análisis anterior, la anomalía se centraba en el ano castrado, en este caso girará en torno al pene como la parte dislocada en el cuerpo de Elisabeth: "como hace para trabajar si tenía partes de hombre". El lenguaje generizado que utiliza Octavio nos remite a monstruos construidos por partes al estilo Frankenstein. Nuevamente, la sinécdoque se utiliza para reducir y cosificar al otro.

Matizando estas operaciones lingüísticas que aparecen en el grupo de varones escuchamos la voz de Estela humanizando al personaje ("seguro no le alcanzaba el dinero"). Esta justificación, si bien convierte al personaje como un sujeto social hace caer sobre él el sentimiento de la compasión. Otro sentido se abre: a Hugo no le quedó otra salida que travestirse por razones económicas.

En suma, ambos grupos de comentarios colocan al sujeto travesti fuera de un género posible, en una zona intermedia innominable, lejana y parodiable. Como explica Gabriel Giorgi,

(...) las retóricas de lo monstruoso permiten ver las gramáticas cambiantes de ansiedades, repudios y fascinaciones que atraviesan las ficciones culturales y la imaginación social; eso que, como escribía Foucault, define las coordenadas de lo prohibido y lo impensable y se condensa en la figuración de un cuerpo irreconocible. (2009, p. 323) 
El aula se desestabiliza ante la posibilidad de otro cuerpo no normado y no lo deja entrar en el imaginario más que como cuerpo monstruoso. El personaje de Hugo/ Elisabeth fue aceptado mientras la ficción lo presentaba escindido. Cuando confluyó en un solo sujeto suscitó el límite en el imaginario del alumnado creando tensiones generizadas, con el personaje y con la profesora.

Las intervenciones de Mariana se ubican a contrapelo de los comentarios de sus alumnos. Ella intenta colocarse, como ya dijimos, en una posición de interpelación del sentido común que reproducen sus alumnos. Su comparación de Elisabeth con un auto para contestarle a Ale opera en este sentido resignificando el término "partes". De esta manera, desnaturaliza la cosificación que intenta plantear el alumno al reducir a Elisabeth a su genitalidad. Por otro lado, es interesante resaltar cómo Mariana va creando categorías analíticas a medida que transcurre la clase. La noción de "lector estafado" es pertinente a la hora de pensar su intervención y los efectos de lectura que ella había previsto. En este sentido, y de la misma manera que trabajó lengua en el incidente anterior, podemos decir que este recorte etnográfico muestra un modo posible de enseñar el saber literario dado por la construcción de personajes y la verosimilitud.

\section{ENTRE LA VOZ Y EL SILENCIO DE LOS CUERPOS}

Una dimensión que se repite en varios incidentes críticos presentes en los autorregistros de Mariana, la profesora en formación, es la tensión entre los estudiantes varones y las estudiantes mujeres al momento de participar oralmente en las clases para comentar hipótesis de lectura o discutir puntos de vista hermenéuticos sobre el texto literario que se está abordando en clase. Por ejemplo, en el autorregistro de la segunda clase, la profesora escribe:

(...) Dado que otra vez estaba replicándose la situación de la clase anterior, con una hegemonía de voces masculinas interpelé a todas las chicas, preguntándoles si ellas notaban que en la clase, casi siempre, la voz que más se escuchaba era la de los varones. Martín me interrumpió para decir que "eso es porque estamos en un mundo machista", yo asentí pero agregando que me gustaría que el espacio de la clase no fuera una copia de lo que pasaba en los demás órdenes de la vida. Las chicas se rieron y Maricel, ofuscada, me dijo que "ellos se escuchan más porque son re quilomberos y hablan fuerte". Les dije que pese a que la mayoría no sabe bien cómo manejar los turnos para hablar, no se trataba de una cuestión de timbre de voz, porque por ejemplo María tenía una voz grave que era fácil de reconocer y oír, pero muchas veces elegía callarse. (...) Les dije que me interesaba y mucho saber qué es lo que ellas pensaban porque estábamos hablando de cuestiones que nos interpelaban directamente. Que no iba a permitir que no opinaran. Recordé algunas de las cuestiones que habían surgido a partir de la lectura del fragmento para que ellas pudieran ofrecer su opinión al respecto. Anoté en el pizarrón piropos entre comillas y debajo acoso callejero (...)

Una situación similar se presenta en la última clase cuando en el texto que están leyendo se narra la violación del personaje de Elizabeth, una prostituta travesti del barrio:

En ese momento empecé a percibir nuevamente el "fantasma del silencio femenino" que siempre atormenta al curso. Quizás sin encontrar la manera más productiva de hacerlo, me puse a preguntarle a cada una qué opinaba de esto que estábamos 
leyendo. La única respuesta que recibía era el gesto de "ni idea" o la vocecita incesante de Martín, que estaba muy enojado con ese silencio de sus compañeras (...).

(...) [L]as chicas se mantenían en la cómoda afasia que tanto me molesta. Esa imposibilidad de obtener una respuesta de las chicas me puso un poco incómoda. Por una parte, porque notaba que pese a que acostumbran no responder, esta vez el silencio funcionaba como un abismo que me costaba superar; y por otra, porque pude darme cuenta que quizás mi interrogación no apuntaba a una respuesta posible, pese al intento de obtener al menos una impresión de su parte.

En estos dos incidentes críticos, la profesora busca la manera de interpelar a las estudiantes, de reflexionar con ellas acerca de la importancia de participar oralmente dando sus opiniones y puntos de vista respecto del texto que están trabajando que, específicamente, problematiza cuestiones referidas a la violencia de género, las representaciones estigmatizantes sobre las mujeres y su confinamiento al espacio doméstico. De algún modo, la mediación docente busca revertir cierta posición social subalterna de las mujeres respecto de los varones -que se reproduce en el aula y que señala en un comentario Martín- que da cuenta de una estructura patriarcal que, como plantea Molina Petit (1994), "se expresa, precisamente, en este poder de asignar un 'sitio' a la mujer" (p. 22) vinculado con lo privado/doméstico, la negación de la autorepresentación femenina y la privación del logos -en tanto y en cuanto, "no es la mujer, precisamente, la que habla ni la que ha hablado de sí" (p. 24)-. En este sentido, los estudiantes varones que, según la estudiante Maricel "se escuchan más porque son re quilomberos y hablan fuerte", son aquellos que utilizan la estrategia lingüística de dominación para controlar la interacción oral (Coates, 2009) que se da en la clase -incluso tratando de silenciar a la profesora en formación- con el objetivo de monopolizar la palabra y reproducir el orden simbólico patriarcal de opresión de las mujeres en el espacio del aula. En este sentido, este accionar de los varones de hablar fuerte para silenciar la voz de las mujeres en el aula -que solo es interrumpido por Martín que trata de que sus compañeras participen y reconoce explícitamente la posición desigual de las mujeres respecto de los varones en el mercado lingüístico- daría cuenta de cómo en el grupo de varones se reproduce, mayoritariamente, la creencia patriarcal de que "el yo femenino es tabú y condición para el yo-contigo patriarcal o mejor dicho el contigo-yo" (Lagarde, 2000, p. 6); es decir, en este orden androcéntrico la expresión de las mujeres debe ser subsidiaria de los varones, los que tienen voz y toman la palabra; o, mejor dicho, las mujeres solo pueden decir con los varones o, si no, refugiarse en la mudez.

En este escenario en el aula, la profesora, a partir de su preocupación por el "fantasma del silencio" y lo que ella llama "la cómoda afasia" de las estudiantes pone en juego, en una clara decisión didáctica, preguntar en forma individual a cada estudiante para conocer sus puntos de vista. Cuando el silencio persiste, la reflexión de la profesora en formación gira en torno a cómo éste se ve reforzado por la sensación de la docente de imposibilidad de romper el orden lógico binario que se instala en el aula, donde las mujeres son ubicadas en una posición satelital respecto de los varones, enmudecidas, silenciadas, acalladas.

De algún modo, la reflexión de la profesora sobre lo que sucede en la práctica gira en torno a su preocupación por cómo las mujeres del grupo se niegan a conectar sus puntos de vista con sus experiencias femeninas, a presentarse en tanto su- 
jetos autónomos que pueden opinar sobre sí mismas y sobre el resto del alumnado sin necesitar el permiso simbólico del varón. En este sentido, la profesora se propone con su intervención didáctica revertir esa dinámica de participación instituida en el grupo, revisar los prejuicios que tienen su estudiantes y proponer otro orden de género que vaya a contrapelo del régimen de género (Butler, 2010) presente en el aula que disciplina y regula según las pautas de la hegemonía masculina y, a su vez, define quiénes hablan o pueden hablar, quiénes callan o quiénes pueden ser o no escuchados y escuchadas en una clara operación de heterodesignación en el aula. De algún modo, la mediación de Mariana ante la mudez de las alumnas busca poner en juego la aculturación feminista (Lagarde, 2000) en tanto práctica de construcción colectiva, de autoconocimiento, de configuración de una conciencia de género y de autoafirmación femenina como ejercicio de resistencia y toma de la palabra de sus estudiantes en el aula. Es decir, Mariana con la interpelación a sus estudiantes y su interés en que participen en el intercambio lingüístico en el aula, apela a la constitución de una identidad femenina consciente de su pertenencia sexo-genérica, de sus valores, derechos, experiencias y saberes.

En relación con ello, es interesante cómo en la primera clase, luego del silencio de las estudiantes mujeres en el intercambio en la puesta en común, cuando viene el recreo, las alumnas se quedan charlando con la profesora y debaten acerca de algunas ideas que sostiene María, una de las estudiantes, acerca de la libertad sexual de una mujer y su vinculación con la prostitución - "si está con varios es una puta, es así"-, en una clara referencia a la sanción moral de la sociedad. La profesora dice que "no se puede juzgar a una mujer por la manera en la que vive su sexualidad o su intimidad" y otra estudiante agrega:

(...) yo hablo de lo que yo sé, pero para mí eso tiene que ver con cómo antes se pensaba la vida de las mujeres y el lugar que ocupaban, que era hacer las cosas de la casa o estar con los hijos y después de los años 60 eso cambió pero mucha gente todavía vive con la mentalidad de antes y no entienden que ahora la mujer es más libre, por eso las juzgan y si hacen algo diferente son putas (...).

La profesora retoma las palabras de esta alumna y propone conversar sobre el lugar de la mujer en la sociedad, los logros, las desigualdades aún vigentes, la no aceptación de los derechos de las mujeres, la falta de comprensión de las subjetividades femeninas y las luchas que todavía quedan por dar. Con su intervención docente, la profesora en formación se propone, por un lado, subvertir la mirada estigmatizante y demonizadora de las conductas sexuales de las mujeres que, en este caso, reproduce María y que da cuenta de una operación de "pánico sexual" (McRobbie, 1998 citada por Elizalde, 2015, p. 48); es decir, "un ejercicio ideológico que se aplica de modo específico sobre ciertas mujeres en razón de su condición de género y de las sospechas morales que pesan sobre ellas por este motivo" (Elizalde, 2015, p. 47). Por otro lado, la mediación docente opera, en esta escena en el recreo, como lazo solidario entre mujeres, como espacio de sociabilidad femenina en el ámbito escolar que, podríamos decir, busca crear un vínculo de sororidad (Lagarde y de los Ríos, 2006) en tanto pacto y encuentro político entre mujeres que se asumen como tales aún en las diferencias y que construyen conocimiento sobre sí mismas en la puesta en práctica de un hacer y pensar con otras. 
La instancia de entrada al campo escolar durante la residencia docente escenifica, también, tensiones en relación con las corporalidades del estudiantado y de la profesora en formación en tanto experiencias corporizadas diversas (Citro, 2011) que responden a prácticas socioculturales y modos de habitar el cuerpo contrapuestos. Mariana registra un incidente a partir de la confesión de Alejandro, uno de los estudiantes, que

contó que con su tío iban una vez en auto y bajaban la ventanilla "para gritarle cosas a unas chicas que iban caminando" y decía que en esa situación se divertían mucho. Le dije a Alex que para él eso puede haber resultado una gracia, pero que muy probablemente las chicas a las que les gritó se hayan sentido muy molestas e incómodas con ese comentario porque en definitiva no le habían preguntado su opinión sobre su cuerpo. Incluso le dije que podrían haber sentido miedo (...).

Esta confesión de Alejandro generó en el grupo alboroto, gritos y muchos circulaban caóticamente por el salón. La profesora les pidió que se ordenaran para poder continuar con el debate. En ese clima, Alejandro "dijo que los varones "siempre están buscando la oportunidad para apoyar", incluso se paró e hizo la mímica" incomodando a la profesora en formación. Esta situación de malestar de Mariana se reforzó, a partir de que otro estudiante, Gustavo, entre risas, hizo referencia a sus características físicas y a su intención de que si la veía en un baile intentaba establecer una relación con ella. La salida a la situación de incomodidad por parte de la docente fue, inicialmente, la risa para luego volver rápidamente al abordaje del texto que estaban analizando.

El intercambio que se produce entre estudiantes varones con las compañeras mujeres y la profesora en formación da cuenta de un orden de género donde los cuerpos masculinos ocupan el espacio del aula, subvierten los ritos de evitamiento propios de la experiencia corporal moderna (Le Breton, 1995) y se presentan como cuerpos vividos en la cercanía de otros cuerpos, incluso de la docente. Aún más, en este incidente podemos observar cierta jerarquía de los cuerpos masculinos sobre los femeninos que "determina entre ellos relaciones de poder y a veces de opresión y de dominio" (Maffía, 2009, p. 219). Asimismo, en esta tensión entre corporalidades se observa la vergüenza e incomodidad de la profesora en contraposición con la apertura y expansión de los cuerpos masculinos, en una clara oposición entre cuerpo replegado de la docente y cuerpos festivos (Diez, 2012) de los estudiantes varones. De allí que, como en otras aulas de escuelas secundarias con profesores y profesoras en formación o en ejercicio, se escenifica cómo Gustavo y Alejandro

(...) 'ejerce[n] el género' (West y Zimmerman, 1999), es decir, ejerce[n] el poder que le da su pertenencia a una masculinidad hegemónica en relación con el grupo y con la profesora en formación en el marco de esa interacción comunicativa, con la intención de establecer el dominio masculino sobre la profesora en formación, sometiéndola a un espacio de subalternidad por ser mujer y, a su vez, reconociendo su posición intermedia como profesora en formación, y no a cargo del curso. (Sardi, 2017, p. 24)

En este incidente crítico registrado por la profesora se refuerza, entonces, la predominancia del patriarcado como sistema de dominación que se ejerce sobre las voces y los cuerpos de las mujeres en el aula, más allá de los roles que ocupen en el ámbito escolar y las posiciones subjetivas que construyan en el espacio público. 


\section{Conclusión}

El espacio del aula en la escuela secundaria durante la residencia docente, como analizamos en este artículo, se configura como un territorio donde las intervenciones didácticas generizadas de la profesora en formación establecen y delimitan modos de vincularse de los sujetos con los saberes disciplinares y de género en una clara tensión entre lo masculino y lo femenino, entre lo hegemónico y lo subalterno. De esta manera, la mediación de la docente en el espacio heteronormativo del aula problematiza, tensiona y visibiliza los estereotipos sexo-genéricos, el orden simbólico androcéntrico, los cuerpos disidentes y las identidades alternativas a partir de las lecturas y análisis del estudiantado en la clase de Lengua y Literatura. En este sentido, como indagamos aquí, la residencia se constituye en una experiencia formativa donde la profesora en formación toma decisiones didácticas, interviene y media en el vínculo entre sujetos y saberes, entre identidades sexo-genéricas y saberes teórico-literarios, entre construcciones culturales y experiencias subjetivas, entre su propio recorrido de la formación disciplinar y su identidad. De allí que el trabajo en la formación docente en Letras en la universidad-como lo venimos pensando en nuestro hacer-se propone poner en el centro la intervención generizada de los y las profesores y profesoras en formación en el terreno de las prácticas docentes en una apuesta por subvertir los presupuestos des-generizados y des-sexualizados que atraviesan la formación inicial docente universitaria.

\section{REFERENCIAS BIBLIOGRÁFICAS}

Aguilar, C. (2009). ¿Por qué es importante el género en la pedagogía crítica? Revista Interuniversitaria de Formación del Profesorado, 64(23,1), 121-138.

Anguita Martínez, R. (2011). El reto de la formación del profesorado para la igualdad. Revista Electrónica Interuniversitaria de Formación del Profesorado, 14(1), 43-51. Recuperado de: http//www.aufop.com.

Ballarín Domingo, P. (2015). Los códigos de género en la universidad. Revista Iberoamericana de Educación, 68, 15-18.

Blanco, R. (2014). Universidad íntima y sexualidades públicas. Buenos Aires, Argentina: Miño y Dávila.

Bolaños Muñoz, L. M. y Jiménez Cortés, R. (2007). La formación del profesorado en género. Revista de Investigación educativa, 25(1), 77-95.

Burbules, N. (1999). El diálogo en la enseñanza. Buenos Aires, Argentina: Amorrortu.

Butler, J. (2002). Cuerpos que importan. Sobre los límites materiales y discursivos del sexo. Buenos Aires, Argentina: Paidós.

Butler, J. (2010). Deshacer el género. Barcelona, España: Paidós.

Citro, S. (Coord.) (2011). Cuerpos plurales. Antropología de y desde los cuerpos. Buenos Aires, Argentina: Editorial Biblos.

Coates, J. (2009). Mujeres, hombres y lenguaje. Buenos Aires, Argentina: Fondo de Cultura Económica. 
Diez, P. (2012). Ni caretas ni quemados, rescatados. Usos del cuerpo y adscripciones identitarias de jóvenes de Bajo Flores Ciudad de Buenos Aires. Alemania: Editorial Académica Española.

Diez Gutiérrez, E. (2015). Códigos de masculinidad hegemónica en educación. Revista Iberoamericana de Educación, 68, 79-98.

Donoso-Vázquez, T. y Velasco-Martínez, A. (2013). ¿Por qué una propuesta de formación en perspectiva de género en el ámbito universitario? Profesorado. Revista de currículum y formación de profesorado, 17(1), 71-88. Recuperado de: http:// www.ugr.es/ recfpro/rev171ART5.pdf.

Elizalde, S. (2015). Tiempo de chicas. Buenos Aires, Argentina: Grupo Editor Universitario.

Fioretti, S. R., Tejero Coni, G. y Díaz, P. (2002). El género: ¿un enfoque ausente de la formación docente? La Aljaba, segunda época, 7, 2-11.

García Herrera, A. P. (2000). El autorregistro como espejo de la práctica. Quaderns Digitals, 1. Recuperado de: http://www.quadernsdigitals.net/index. php?accionMenu=hemeroteca.VisualizaArticulolU.visualiza\&articulo_id=3640.

Giorgi, G. (2009). Política del monstruo. Revista Iberoamericana, 75(227), 323-329.

Jiménez Cortés, R. (2007). Discurso de género y práctica docente. Revista de Investigación Educativa, 25(1), 59-76.

Kristeva, J. (1988). Poderes de la perversión. Buenos Aires, Argentina: Siglo XXI.

Lagarde y de los Ríos, M. (2006). Pacto entre mujeres Sororidad. Ponencia presentada en Coordinadora española para el lobby europeo de mujeres, Madrid. Recuperado de: http://pmayobre.webs.uvigo.es/textos/marcela_lagarde_y_de_los_rios/sororidad.pdf.

Lagarde, M. (2000). Aculturación feminista. En E. Largo (Ed.). Género en el Estado. Estado en el género. Santiago de Chile, Chile: Ediciones de las mujeres.

Le Breton, D. (1995). La sociología del cuerpo. Buenos Aires, Argentina: Ediciones Nueva Visión.

Lesbereguis, M. (2014). ¡Niñas jugando! Ni tan quietas ni tan activas. Buenos Aires, Argentina: Editorial Biblos.

Maffía, D. (2009). Cuerpos, fronteras, muros y patrullas. Revista científica de Universidad de Ciencias Empresariales y Sociales, 12(2), 217-226.

Marrero, A. y Mellada, N. (2009). La universidad transformadora. Montevideo, Uruguay: Facultad de Ciencias Sociales Universidad de la República.

Molina Petit, C. (1994). Dialéctica feminista de la Ilustración. Barcelona, España: Anthropos.

Mora, E. y Pujol, M. (2009). Introducción de la perspectiva de género en la universidad. Ponencia presentada en el Congreso Internacional Univest 2009, Girona. Recuperado de: http://dugi-doc.udg.edu/bitstream/handle/10256/2017/210. pdf? sequence $=1$.

Palermo, Z. (Ed.) (2014). Para una Pedagogía Decolonial. Buenos Aires, Argentina: Ediciones del signo.

Perrenoud, Ph. (1995). El trabajo sobre los "habitus" en la formación de los enseñantes. Análisis de las prácticas y toma de conciencia. Faculté de psichologie et de sciences de l'education. 
Preciado, B. (2013). Terror anal. Manifiestos recientes. Buenos Aires, Argentina: La Isla de la Luna.

Privat, J.-M. (2001). Sociológicas de la didáctica de la lectura. Lulú Coquette. Revista de Didáctica de la lengua y la literatura, 1(1), 47-63.

Rockwell, E. (1995). Huellas, bardas y veredas. En E. Rockwell. (1995). La escuela cotidiana. México, México: Fondo de Cultura Económica.

Rodríguez González, C. (2010). La recreación de Andrógino y sus representaciones en el arte y los mass media: un estudio etnográfico sobre los roles de género. Memoria para optar al grado de doctor, Universidad Complutense de Madrid.

Sardi, V. (2017). Prácticas en terreno/prácticas generizadas en la formación docente en Letras. En V. Sardi (Coord.), Jóvenes, sexualidades y saberes en la escuela secundaria (pp. 15-44). Buenos Aires, Argentina: Grupo Editor Universitario.

Valentino, E. (2008). Perros de nadie. Buenos Aires, Argentina: Ediciones SM.

West, C. y Zimmerman, D. (1999). Haciendo género. En M. Navarro y C. Stimpson (Comps.), Sexualidad, género y roles sexuales (pp. 109-143). Buenos Aires, Argentina: Fondo de Cultura Económica.

Zabalza, M. A. (2004). Diarios de clase. Un instrumento de investigación y desarrollo profesional. Madrid, España: Narcea Ediciones. 